University of Montana

ScholarWorks at University of Montana

$4-2010$

\title{
Funding Needed for Assessments of Weed Biological Control
}

John L. Maron

University of Montana - Missoula, john.maron@mso.umt.edu

Dean E. Pearson

Stephen M. Hovick

Walter P. Carson

Follow this and additional works at: https://scholarworks.umt.edu/biosci_pubs

Part of the Biology Commons

Let us know how access to this document benefits you.

\section{Recommended Citation}

Maron, John L.; Pearson, Dean E.; Hovick, Stephen M.; and Carson, Walter P., "Funding Needed for Assessments of Weed Biological Control" (2010). Biological Sciences Faculty Publications. 241.

https://scholarworks.umt.edu/biosci_pubs/241

This Letter to the Editor is brought to you for free and open access by the Biological Sciences at ScholarWorks at University of Montana. It has been accepted for inclusion in Biological Sciences Faculty Publications by an authorized administrator of ScholarWorks at University of Montana. For more information, please contact

scholarworks@mso.umt.edu. 
Use of dose-response in place of an ANOVA-based approach requires thinking a bit differently about experimental design and analysis. Such studies often begin with a range-finding experiment, in order to efficiently bracket test-subject response between doses that produce low response rates and doses that produce responses in all test subjects. Whereas differences in survival are typically tested with ANOVA, it is mortality that is analyzed in dose-response.

Ecologists could use a dose-response model at scales not typically seen in toxicology. The response of whole communities or ecosystems to varying doses of large-scale, non-traditional stressors could be examined - evaluating the presence of tipping points and providing hypotheses for temporal responses to increasing levels of stress. Such applications would not be without caveats, of course. In the case of large-scale ecological application of dose-response designs, there may be practical limits to maximum doses that can be produced in the field, resulting in truncated response curves.

As a "classically" trained ecologist, I was biased toward ANOVA until I conducted my own toxicological studies as a postdoc. I suspect that underappreciation or ignorance of the dose-response design is a product of canalization between training in basic and applied fields of study. Yet basic and applied ecology increasingly overlap, as the importance of the science underlying environmental issues increases. Thus, as ecologists - not otherwise trained as toxicologists lead studies that blur the distinctions between ecology and toxicology, appropriate quantitative methodology should follow.

\section{David F Raikow}

US Environmental Protection Agency, Cincinnati, OH (raikow.david@epa.gov)

Cottingham KL, Lennon JT, and Brown BL. 2005. Knowing when to draw the line: designing more informative ecological experiments. Front Ecol Environ 3: $145-52$.

No Agency positions are established in this expression of the author's views.

doi:10.1890/10.WB.011

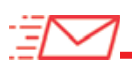

\section{A disappointing end}

In the Dispatches section of the September issue of Frontiers (Front Ecol Environ 2009; 7[7]: 349), Virginia Gewin's article, "FACE facing the end", discussed the termination of the Free Air Carbon Dioxide Enrichment (FACE) experiments and the unique insights into the influences of increased levels of atmospheric $\mathrm{CO}_{2}$ on forest carbon dynamics gained as a result of that research. Although there is undoubtedly much to be learned by ending the experiments, harvesting the trees, and excavating soils and roots - the results of those measurements will certainly be enlightening - it seems as though the results of the FACE experiments themselves to date have demonstrated that its continuation is scientifically valuable and justified. Indeed, a number of results have shown unexpected temporal shifts in ecological responses, thus raising questions concerning the continued evolution of these ecosystems over the longer term, under elevated atmospheric $\mathrm{CO}_{2}$ conditions. That being said, what is the "longterm" value of this type of ecological systems research, and should experiments such as FACE be extended?

To answer the first question, we need look no further than the Long Term Ecological Research (LTER) network to understand the benefits and scientific value in creating and maintaining a permanent network of research sites and experiments. While the scope and mission of the FACE experiments are fundamentally different from those of the LTER network, they are nevertheless a distinctive and critical set of experiments that should be maintained indefinitely, lest a landmark project on climatechange research be shuttered. The temporal scale and ingenuity of the FACE experiments have provided, if nothing else, a unique opportunity for scientific inquiry.

An answer, or rather an opinion, on the second question is that FACE and similar long-term investigations should indeed be continued. Longterm research is an invaluable asset in natural systems science and "in the absence of the temporal context provided by long-term research, serious misjudgments can occur...in our attempts to understand and predict change in the world around us" (Magnuson 1990). Without the continuation of the FACE experiments, even on a limited scale, it seems a valuable temporal perspective has been sacrificed, thereby limiting our long-term understanding of terrestrial ecosystems in a changing climate.

James E Bedison

Department of Earth $\mathcal{E}$ Environmental Science, University of Pennsylvania, Philadelphia, PA

(jbedison@sas.upenn.edu)

Magnuson JJ. 1990. Long-term ecological research and the invisible present. BioScience 40: 495-501.

doi:10.1890/10.WB.012

\section{$\triangle$ \\ Funding needed for assessments of weed biological control}

Invasive non-native plants are a serious economic and ecological problem worldwide, and major efforts are therefore devoted to reducing weed abundance in agricultural and natural settings. Effective options for reducing invasive abundance and spread are few, although one common approach is biological control the introduction of specialist herbivores or pathogens from a weed's native range to suppress weed abundance in the introduced range. Biocontrol is a crucial tool in invasive species management because, once biocontrol agents establish, they are often self-sustaining and can greatly reduce invasive populations.

Yet, as with all weed control efforts, biocontrol has its costs. Establishing a new biocontrol program is expensive, costing well over US $\$ 1000000$ for the discovery, testing, rearing, and release of specialist enemies against a single target weed (Page and Lacey 2006). Weed biocontrol has also been 
controversial because of the ecological risks associated with releasing exotic enemies into recipient communities. As with many controversies, this one is fueled by a fundamental lack of information. Few rigorous scientific assessments have evaluated the amount and extent of target weed suppression and the side effects that can occur following the release of biocontrol agents. Whether reductions in target-weed abundance lead to invasion by secondary invaders or recovery by desired plants has also been poorly documented. The issue isn't whether biocontrol can work; it clearly can (Gurr and Wratten 2000). Rather, the issue is how often does it work and under what circumstances? Answering these questions requires rigorous postrelease evaluations in order to advance the science and improve the efficacy of future programs.

Despite often heated debate about the relative merits of biological control, all parties would agree that quantifying biocontrol outcomes is essential (Müller-Schärer and Schaffner 2008). Current regulations not only request detailed pre-release studies, addressing the host specificity and impact of potential biocontrol agents, but they also require that post-release monitoring plans be in place. Yet, the reality is that careful quantitative assessment of biocontrol outcomes often falls through the cracks. When prudent evaluation does happen, it is often through the fortuitous collaboration of academic scientists with biocontrol practitioners. There are exceptions (Shea et al. 2005), but past efforts documenting biocontrol outcomes in weeds have mostly been cor- relative, where treatment populations receiving biocontrol agents are monitored but control populations are not (Julien and Griffiths 1998).

The crux of the issue is simple: although funds can be obtained to search for new biocontrol agents, test for their host-plant specificity, and rear and release them, money for postrelease assessment is usually lacking. This does not reflect a failure on the part of the land managers and biocontrol scientists, who are struggling to cope with an expanding weed problem. Rather, it highlights a crucial limitation of the current funding and regulatory structure for biological control, which encourages and funds new biocontrol efforts without having a mechanism to ensure that their outcomes are rigorously assessed. Changing current practices will require concerted lobbying on behalf of the scientific community. The federal government and states must mandate that outcomes from biocontrol introductions be assessed and should fund those assessments as well as their documentation. This will provide benefits beyond simply quantifying when and where target weeds are suppressed: they may help identify the mechanisms by which weed control occurs in community "recovery", elucidate the conditions that increase the likelihood of biocontrol success, and reveal the reasons for failure. Mandating clear monitoring guidelines, having unambiguous definitions for what constitutes "success", and providing adequate funding to assess whether biological control is safe, effective, and necessary are essential for advancing the science underlying this crucial weed management tool.

John L Maron ${ }^{1 *}$, Dean E Pearson ${ }^{2}$,

Stephen M Hovick ${ }^{3}$, and

Walter P Carson ${ }^{4}$

${ }^{1}$ Division of Biological Sciences, University of Montana, Missoula, MT *(john.maron@mso.umt.edu);

${ }^{2}$ Rocky Mountain Research Station,

US Forest Service, Missoula, MT;

${ }^{3}$ Department of Ecology and

Evolutionary Biology, Rice University,

Houston, TX; ${ }^{4}$ Department of

Biological Sciences, University of

Pittsburgh, Pittsburgh, PA

Gurr G and Wratten S. 2000. Biological control: measures of success. Dordrecht, Netherlands: Kluwer Academic Publishers.

Julien MH and Griffiths MW. 1998. Biological control of weeds: a world catalogue of agents and their target weeds, 4th edn. Wallingford, UK: CABI Publishing

Müller-Schärer H and Schaffner U. 2008. Classical biological control: exploiting enemy escape to manage plant invasions. Biol Invasions 10: 859-74.

Page AR and Lacey KC. 2006. CRC for Australian weed management $\# 10$. Glen Osmond, Australia: CRC for Australian Weed Management.

Shea K, Kelly D, Sheppard AW, and Woodburn TL. 2005. Context-dependent biological control of an invasive thistle. Ecology 86: 3174-81.

doi:10.1890/10.WB.013

\section{Erratum}

In the letter from David Pimentel (2010: 8[2]: 66) the text should read, "based on its current growth rate, [Earth's] population will double within 58 years." (not 13 years, as stated).

\section{TAKE THIS JOURNAL TO YOUR LIBRARIAN, PLEASE} Are you enjoying this issue of Frontiers?

If your library had a subscription, colleagues and students could enjoy it too. Please consider recommending Frontiers in Ecology and the Environment to your library (ISSN 1540-9295).

\section{Thank you for your support}

You can obtain a subscription to Frontiers in Ecology and the Environment by contacting ESA Headquarters (+1 2028338773 ), online at www.esa.org, or through your subscription agent. To request a free sample issue, call or email Eric Gordon (eric@esa.org). 